\title{
Rateio de custos como alternativa de proteção e recuperação da bacia hidrográfica do Rio Pardo
}

\author{
Verushka Goldschmidt Xavier de Oliveira ${ }^{1}$ \\ Markus Erwin Brose ${ }^{2}$ \\ Valéria Borges Vaz ${ }^{3}$
}

\begin{abstract}
Resumo
A lei federal 9.433/1997, que instituiu o Sistema Nacional de Gerenciamento de Recursos Hídricos, previu diversos instrumentos de gestão e planejamento das bacias hidrográficas e estruturas para seu funcionamento integrado. Porém, os instrumentos de Gestão-Cobrança pelo Uso da Água e as estruturas de Agências de Bacias ainda não foram implementados em muitos Estados e este é o caso do Rio Grande do Sul. Considerando que a cobrança fosse implementada haveria recursos para investimento na bacia hidrográfica e manutenção operacional do sistema. Assim, com a ausência deste instrumento, o Rateio de Custo de Obras de Uso e Proteção dos Recursos Hídricos, previsto na lei estadual 10.350/1994, passa a ser uma alternativa para implementar o Plano da Bacia. E para fechar o ciclo da gestão integrada uma alternativa para a inexistência das estruturas de Agências de Bacias são as Organizações Jurídicas de Direito Privado, com vários exemplos no Brasil. Sentindo-se provocados pela morosidade de implementar o sistema gaúcho na sua totalidade, o Comitê de Gerenciamento da Bacia Hidrográfica do Rio Pardo debruçou-se em estudar e aplicar estas alternativas para dar seguimento à gestão das águas da Bacia do Rio Pardo.
\end{abstract}

Palavras-chave: Comitê de Bacia; Agência de Bacia; Uso e proteção de recursos hídricos; Bacia hidrográfica.

\section{Cost apportionment as an alternative for protection and recovery of the Rio Pardo watershed}

\begin{abstract}
Federal law 9.433 / 1997, which instituted the National Water Resources Management System, provided for various management instruments and planning of river basins and structures for their integrated operation. However, the management instrument called Charging for Water Use and the structures of Basin Agencies have not yet been implemented in many States and this is the case in Rio Grande do Sul. Developing Charging to be implemented, there were resources for investment in the hydrographic basin and operational maintenance of the system. Thus, with the absence of this instrument, the Cost of Works and Protection of Water Resources Index, provided for in state law 10.350/1994, becomes an alternative for the implementation of the Basin Plan. And to close the cycle of integrated management, an alternative to the absence of the structures of Basin Agencies is the Private Law Legal Organizations, with several examples in Brazil. Feeling provoked by the slow inertia of implementing the entire Rio Grande do Sul system, members of the Rio Pardo River Basin Management Committee focused on studying and applying these alternatives to continue the management of the waters of the Rio Pardo Basin.
\end{abstract}

Keywords: Basin Committee; Basin Agency; Use and Protection of Water Resources; Hydrographic basin.

\footnotetext{
${ }^{1}$ Mestranda do Programa de Pós-graduação em Desenvolvimento Regional da UNISC. Bolsista CAPES PROSUC II. https://orcid.org/0000-0001-5377-6839.verushkagxavier@gmail.com

2 Doutor em Sociologia (Universidade de Osnabrück-DE). Pós-Doutor em Desenvolvimento Regional pela Universidade de Santa Cruz do Sul (UNISC). Professor do Programa de Pós-Graduação em Desenvolvimento Regional da Universidade de Santa Cruz do Sul (UNISC). https://orcid.org/0000-0003-0539-8292. markus@unisc.br
}

${ }^{3}$ Mestre em Planejamento Urbano e Regional (UFRGS). Presidente Comitê Pardo e Coordenadora do Fórum Nacional de Comitês de Bacias. https://orcid.org/0000-0002-1137-0934.valeriaborgesvaz@gmail.com 


\section{Introdução}

Fazer o planejamento do território perpassa pensar a governança territorial. Neste estudo, será utilizado o caso do Comitê de Gerenciamento da Bacia Hidrográfica do Rio Pardo, ou Comitê Pardo, que ao unir usuários da água, representantes da população e poder público, faz o planejamento de uma área denominada bacia hidrográfica, que tem um recorte físico, mas também aspectos territoriais. Na concepção de Milton Santos, outros fatores necessitam ser estudados e analisados, como as relações de poder, hegemonia de alguns atores no processo e formação socioespacial na discussão sobre o território.

Ao participar de uma política de recursos hídricos, os membros do Comitê Pardo acabam por definir os rumos do território, pois, diferentemente dos limites municipais, que são estabelecidos por articulações políticas, o território da bacia hidrográfica inclui vários municípios. Assim, ao planejar algo para determinado local da bacia haverá reflexos em todo o espaço da bacia, pois o rio é dinâmico e de abrangência regional. O uso e ocupação do território por sua vez têm impactos positivos e negativos exigindo, portanto, uma gestão integrada efetiva para planejar o futuro da bacia.

Então, de posse da legislação de competência dos recursos hídricos, aos quais os Comitês de Bacias estão subordinados, implementou-se o planejamento participativo na bacia. O Comitê Pardo, com o intuito de fazer sua parte, se apropriou da legislação vigente e encontrou alternativas para os entraves do sistema com o propósito de colocar em prática ações que possam, de fato, resultar numa melhoria da quantidade e qualidade das águas da Bacia do Pardo. Um desses instrumentos chama-se Cobrança pelo Uso da Água, definido pela lei federal 9.433/1997 (Brasil, 1997), que no caso do Rio Grande do Sul não está implementado. Com os valores arrecadados por este instrumento seria possível manter o sistema operacional dos comitês e aplicar os recursos financeiros para oferecer a contrapartida de projetos executivos de recuperação da bacia.

O objetivo do estudo que gerou este artigo foi analisar e apresentar o caminho trilhado pelo Comitê Pardo até chegar aos dois mecanismos alternativos, que são: a criação de uma organização jurídica de direito privado, a definição dos critérios de Rateio de Custo de Obras de Uso e Proteção dos Recursos Hídricos, e ainda tratar do processo de construção conjunta para a elaboração de Termo de Referência (TR) para Recuperação do Rio Pardinho. Esses mecanismos visam propor alternativas para que o Sistema de Recursos Hídricos possa avançar e 
operacionalizar as ações que necessitam ser realizadas para a recuperação da bacia hidrográfica possam se efetivar.

\section{Território da bacia hidrográfica: poder e planejamento}

Com a Constituição Federal de 1988, houve no Brasil a possibilidade de participação da sociedade civil nas questões envolvendo as políticas públicas. O ato de representação faz parte de um processo de governança que visa, dentre tantos aspectos, estabelecer estratégias para o desenvolvimento mediante acordos com os atores envolvidos enquanto mecanismo de controle e regulação do território, situando-se entre o local e o regional, unido forças verticais e horizontais. Assim, na tentativa de solucionar eventuais problemas de ordem econômica, social, política, ambiental de um local, é feito o planejamento regional. Quanto aos recursos hídricos, a governança é entendida como processo e a gestão como a prática. A governança envolve tanto a gestão administrativa do Estado como a capacidade de articular e mobilizar os atores estatais e sociais para resolver dilemas de ação coletiva (OGA, 2020).

Quanto ao território e sua definição como espaço de articulação de estratégias de desenvolvimento, há de se lidar com políticas setoriais e territoriais. Ainda se observa que o próprio conceito de território é modificado a partir de diversos interesses. Portanto, primeiramente é preciso diferenciar espaço de território (FLORES 2006). Raffestin (1993) considera que o espaço é anterior ao território e define espaço como o patrimônio natural e território como a apropriação deste espaço por atores através de suas relações, de modo que território seria um jogo de poder num dado espaço. O território ainda possuiria superfícies, pontos e redes.

Pecqueur (2009) considera que é necessário diferenciar dois tipos de territórios, um que se define nas instâncias político-administrativas, em processo top-down, de cima para baixo, e que seria o território dado, e outro chamado de construído, ou usado, no qual os atores se reúnem num espaço geográfico e procuram identificar e resolver problemas comuns.

Para Santos (1996) o espaço geográfico é híbrido, pois une sistemas de objetos e ações, onde o objeto se refere a configurações territoriais e as ações correspondem aos sujeitos que vão se instalar para criar o espaço, considerando fato e fator social. Assim, ao se considerar o espaço material, é preciso focar no aspecto físico, a saber: espaço natural e produtos de trabalho; e o espaço social seria o imaterial, ou seja, as redes. Santos (1999) fala que o território não seria 
uma categoria de análise, mas sim o território usado. A ciência política, para o autor, se atenta aos municípios e estados, mas não ao território, como se ele não fosse social. Deste modo, o território usado seria um cenário em transformação, que une passado e futuro. Ou seja, o território é um objeto que deve ser interpretado enquanto lugar de relações de poder. Para Haesbaert (2007), esse poder não se refere ao poder político, mas o de dominação no território enfatizando que há a imbricação de múltiplas relações de poder abrangendo o material e o simbólico.

Para Raffestin (1993), a geografia política tratou de fazer uma divisão tripartite em seu estudo: população, território e recursos. Assim, conflitos que envolvem disputa de territórios expõem a luta de populações pelos recursos existentes, renováveis ou não, mas que são ou podem vir a ser instrumentos do poder. Dos três objetos de estudo da geografia política, é na população que se estabelece e se visualiza a dinâmica do poder através das relações que possuem os seus habitantes. O território é um espaço político por natureza, e o poder se manifesta nas relações através de trocas ou comunicação entre dois agentes, ou duas forças, transformando-se em um campo de poder. Nesta dinâmica, entende-se que toda relação ocupa um lugar de poder, que engloba energia e informação, e esta informação poderia ser repassada com sinais linguísticos ou não através dos sinais.

Bourdieu (1998) caracteriza o poder como campos de forças, onde os atores desenvolvem relações de poder e que se reproduzem nas relações sociais. Dessa maneira, a relação de poder está definida pela relação social e qualidade da relação que é mantida entre os atores de um território. Para o autor, o campo de poder é diferente de político, pois abrangeria diversos tipos de capital, que poderiam ser: econômico, social, cultural ou simbólico, sendo este último um poder invisível, e que pode se constituir numa identidade territorial. O poder estaria localizado dentro dos campos sociais, se considerarmos o habitus e o capital simbólico.

Raffestin (1993) fala da contribuição de Focault citando algumas proposições deste autor sobre o poder, e destaca que o poder não se adquire, mas é exercido; as relações de poder são intencionais e não subjetivas e onde há poder, há resistência. Se o poder é intencional, por consequência há uma finalidade, ou seja, prevalece a vontade do grupo hegemônico e essa se manifesta sobre o território. Sobre o poder, Arendt (2007) diz que este é apenas um potencial e que a convivência entre os homens seria o fator para gerá-lo. Depreende-se daí que o poder só seria possível através do coletivo resultando relações que advém dos interesses das instituições. 
Estas relações podem se qualificar nas múltiplas faces do poder, conforme Palheta da Silva (2009), citando as encontradas nas estruturas político-econômicas, cujos interesses interferem no local e também podem ser fragmentadas, pois se constituem de alianças, na medida em que os atores possuem interesses comuns, transformando o poder numa relação instável, pois se refaz a todo momento. Caso ocorra uma modificação de relações no território, elas serão reformuladas, em que pese o fato do compartilhamento de interesses comuns, através do estabelecimento de novas alianças dos atores do território. Há que se convencer o outro, através do poder de origem formal (instituições políticas) ou informal (sociedade civil).

Kauffman (2012) cita Granovetter, quando este afirma que os indivíduos tomam decisões mais consistentes quanto mais coesa é a relação destes através dos vínculos. Menciona as relações interpessoais, ou os laços fortes e laços fracos, abordados por Granovetter. Os laços fracos ao terem pouco envolvimento social, como no caso dos atores que se encontram com menor frequência, são menos efetivos que os laços fortes tidos com amigos mais próximos, ou os de intenso contato social e afinidade. Os laços fracos dinamizam as redes, enquanto os fortes as fortalecem e dão consistência. A rede é um capital social que exerce influência, em maior ou menor trânsito. A pergunta que fica é: por que alguns atores possuem mais laços e transitam em mais redes que outros e como efetuam esses laços e relações interpessoais?

Conforme Raffestin (1993), poder e saber estão imbricados, o que corrobora a afirmação de Focault quando este diz que poder produz saber, de forma que a produção do conhecimento não é útil ao poder, mas é através da relação poder-saber e os processos de luta que determinam as formas e campos dos conhecimentos (FOCAULT, 2011, p. 31). Focault analisou o poder do Estado, sobretudo em uma prisão, e das instituições de ensino sobre os corpos dos cidadãos, transformando-os em dóceis e disciplinados. O poder, antes sobre os corpos em si, numa tentativa de manipulação e adestramento, séculos depois passou a ser realizado através da disciplina do corpo. De toda forma, para Focault, o poder não está nas mãos de um ator, mas nas relações, através da disciplina. Mas nem só o Estado domestica os corpos, diz Raffestin (1993), e para isso estabelece a divisão em atores sintagmáticos (o Estado) e os paradigmáticos. No caso em análise, as práticas de governança e estratégias definidas de modo conjunto entre os atores envolvidos no processo materializam o conceito de Focault especialmente diante da possibilidade de produção de conhecimento e da irradiação social que as práticas de gestão dos recursos hídricos possuem nos territórios em que são implementadas. 
Brito; Anjos (2010) atentam para o fato de que muitas vezes o território é subtraído da noção de bacias hidrográficas, e estas acabam sendo tratadas apenas como recursos hídricos, isto é, como corpos d'água propriamente ditos. Segundo Tucci (1997), a bacia hidrográfica compõe-se de um conjunto de superfícies vertentes e de uma rede de drenagem formada por cursos de água que confluem até resultar em um leito único no seu exutório, ou seja, é uma área de captação natural da água de precipitação que faz convergir o escoamento para um único ponto de saída. Em linhas gerais é sobre esse território chamado bacia hidrográfica que se manifestam as produções antrópicas, ou humanas, sejam elas, industriais, agrícolas, de preservação e outras. Para facilitar o processo de compreensão, dividiu-se o país em várias regiões hidrográficas, que seria o aspecto macro. Neste formato, 12 regiões e suas divisões se justificariam a partir das diferenças existentes nos quesitos ecossistema, produção, economia, e aspectos socioculturais, em configuração física e características locais. Não obstante, como recorte territorial, deve-se levar em consideração o exercício do território nas três esferas de competência: União, Estados e municípios, no tocante à gestão do bem comum que é a água. (PORTO; PORTO, 2008).

Desse modo, as bacias hidrográficas por terem um recorte diferenciado do recorte municipal, apresentam uma diferenciação quanto ao planejamento, pois a sua área de abrangência perpassa vários municípios. Estariam adequadas ao planejamento ambiental, mas nem sempre apropriadas para o planejamento e gestão de outras políticas setoriais. Dessa forma, se está tratando de governança, que no caso dos Comitês de Bacias vem a ser a governança territorial, na qual diversos atores de instituições e organizações da sociedade civil exercessem as suas redes de poder sócio-territorial.

Os Comitês de Bacias Hidrográficas, como exemplo de governança territorial, são responsáveis pela gestão das águas, apoiados na lei federal 9.433/1997 (Brasil, 1997), que estabeleceu o Sistema Nacional de Gerenciamento de Recursos Hídricos (SINGREH), com diversas instâncias, desde o âmbito federal, com o Conselho Nacional de Recursos Hídricos, passando pelos Conselhos Estaduais de Recursos Hídricos. Em âmbito regional os Comitês de Bacias são colegiados deliberativos nas unidades de planejamento e gestão. O SINGREH permitiu a participação de usuários e sociedade civil em cada esfera. Os Comitês, sendo compostos por usuários, sociedade civil e representantes do poder público, visam a gestão dos recursos hídricos, com o uso de instrumentos que a lei preconiza, e têm a função de mediar possíveis conflitos pelo uso da água. Como a área de planejamento e gestão é a bacia hidrográfica, antes da criação dos 
Comitês o planejamento se fazia em âmbito municipal e Estadual e as informações eram dispersas, o que dificultava o planejamento (PIRES; FUINI; MANCINI; PICCOLI NETO, 2011; PIRES; NEDER, 2008).

Considerando que a água é um elemento estratégico para o desenvolvimento regional, haja vista que é utilizada para abastecimento, irrigação, criação animal, uso industrial, geração de energia e demais usos múltiplos, é de fundamental importância que seja valorizada no contexto. Para além da questão econômica atrelada ao tema recursos hídricos, há ainda o saneamento básico, que promove a qualidade de vida de cidadãos na medida em que há tratamento de água e esgoto, mais reforçada a necessidade de ambos diante da pandemia do novo coronavírus (COVID-19). Ou seja, fatores econômicos, de qualidade de vida e de desenvolvimento estão conectados quando o assunto é água.

O uso de atividades intensivas de recursos hídricos poderia ser comparado ao postulado de Adam Smith, no paradoxo da água e diamante, quando fala sobre o valor de uso e de troca, no qual as coisas com uso mais frequente têm menor valor de troca. Ou seja, a água apesar de muito usada, nada valeria como troca para compra de outro produto, ao contrário de um diamante, que não tem muito uso, mas é raro e com alto valor de troca. Ainda que a discrepância entre os valores de mercado da água e do diamante seja incontestável, no aspecto ambiental, social e econômico contemporâneo, analisando-se a questão da vida e sobrevivência dos povos especialmente diante das mudanças climáticas, não restam dúvidas quanto à relevância - e valor - da água.

\section{As legislações nacional e estadual sobre recursos hídricos}

Quanto à lei federal 9.433/1997 (Brasil, 1997), esta previu diversos meios de gestão e planejamento das bacias hidrográficas. Um dos instrumentos de gestão é a Cobrança pelo Uso da Água, que não é um imposto ou tarifa, como o pago no caso das concessionárias de abastecimento nos municípios, mas sim uma remuneração pelo uso de um bem comum que é a água. Neste caso, o usuário da água, que capta ou lança efluentes nos cursos d'água, deveria ser o responsável por pagar esta conta. Mas para ser um processo transparente e com a participação de toda a sociedade é que este assunto é tratado nos Comitês de Bacias Hidrográficas, onde três grupos de atores definem os valores da cobrança: usuários, representantes da população e poder público. Como previsto na lei federal, estes recursos poderiam ser utilizados para financiamento de projetos de recuperação da bacia hidrográfica e manutenção operacional do sistema. 
Mas para haver cobrança é necessário o estabelecimento de uma Agência de Bacia, uma entidade que além da arrecadação, prestaria suporte técnico e administrativo aos Comitês de Bacias. O Sistema foi muito bem pensado na legislação, mas na prática há entraves. Vejamos o exemplo do Rio Grande do Sul. Em 1994, houve a publicação da lei estadual 10.350/1994 (Rio Grande do Sul, 1994), que instituiu o Sistema Estadual de Recursos Hídricos no Rio Grande do Sul (SERH), e foi protagonista no estabelecimento desta política com os mesmos instrumentos de gestão e planejamento elencados na lei federal 9.433/1997. Porém, no Rio Grande do Sul não existem as Agências de Bacias, que por lei deveriam ser três, sendo uma para cada região hidrográfica, quais sejam, para as regiões hidrográficas do Guaíba, do Litoral e do Uruguai. Até hoje, passados quase 26 anos da publicação da lei estadual, nunca houve a instituição de uma Agência de Bacia.

Quanto aos demais instrumentos de planejamento e gestão previstos na lei estadual, pode-se dizer que há planos de bacias e enquadramentos definidos em alguns comitês (se ainda incompletos, ao menos em algum ponto de estruturação) e sistema de outorga, cujo cadastro é realizado pelo próprio usuário, de forma virtual. Quanto aos entes do SERH, todos estão constituídos, sendo que os primeiros Comitês de Bacias foram instituídos em 1988 e o último em 2012, totalizando 25 organizações com este modelo. O Comitê de Gerenciamento da Bacia Hidrográfica do Rio Pardo, ou Comitê Pardo, objeto deste estudo, foi criado em 1998, através do decreto estadual 39.116/1998 (Rio Grande do Sul, 1998) e instalado em 1999 (COMITÊ PARDO, 1999).

\subsection{A bacia hidrográfica do Rio Pardo}

A bacia hidrográfica do Rio Pardo faz parte da região hidrográfica do Guaíba, e tem área de $3.636,79 \mathrm{~km}^{2}$, correspondendo a 1,3\% da área do Estado e a 4,3\% da área da Região Hidrográfica do Guaíba (PLANO DE BACIA, 2005). Abrange os municípios de Barros Cassal, Boqueirão do Leão, Candelária, Gramado Xavier, Herveiras, Lagoão, Passa Sete, Rio Pardo, Santa Cruz do Sul, Sinimbu, Vale do Sol, Venâncio Aires e Vera Cruz, conforme Figura 1.

A área de bacia hidrográfica é diferente de área de município, sendo uma área de planejamento que deveria ser considerada em outros planos setoriais, de domínio dos municípios. A bacia do rio Pardo conta com dois rios: Pardo e Pardinho.

Conforme o Plano de Bacia (2005), a área da bacia pode ser dividida em três porções: a) $20 \%$ na parte alta, onde se encontrariam as nascentes dos rios Pardo (Barros Cassal) e Pardinho 
(Boqueirão do Leão), com atividades primárias e extensas áreas de campos, encontrando-se aí os municípios de Barros Cassal, Boqueirão do Leão, Gramado Xavier e Lagoão; b) 40\% porção intermediária, com relevo abrupto da encosta do Planalto, com predominância de propriedades coloniais, onde se localizam os municípios de Herveiras, Passa Sete, Sinimbu e Vale do Sol; c) 40\% de porção mais a jusante, com áreas mais planas e nas áreas de várzea cultivo de arroz irrigado, e nas áreas mais elevadas com a pecuária extensiva e para o cultivo agrícola de tabaco e soja, por exemplo. É nesta porção que se encontram os municípios de Candelária, Rio Pardo, Vera Cruz e Santa Cruz do Sul, responsáveis pelo maior núcleo urbano da bacia. Apenas os municípios de Herveiras, Vale do Sol e Vera Cruz têm a área municipal totalmente contemplada pela área da bacia hidrográfica (Figura 1).

Figura 1 - Mapa dos municípios da Bacia Hidrográfica do Rio Pardo/RS 


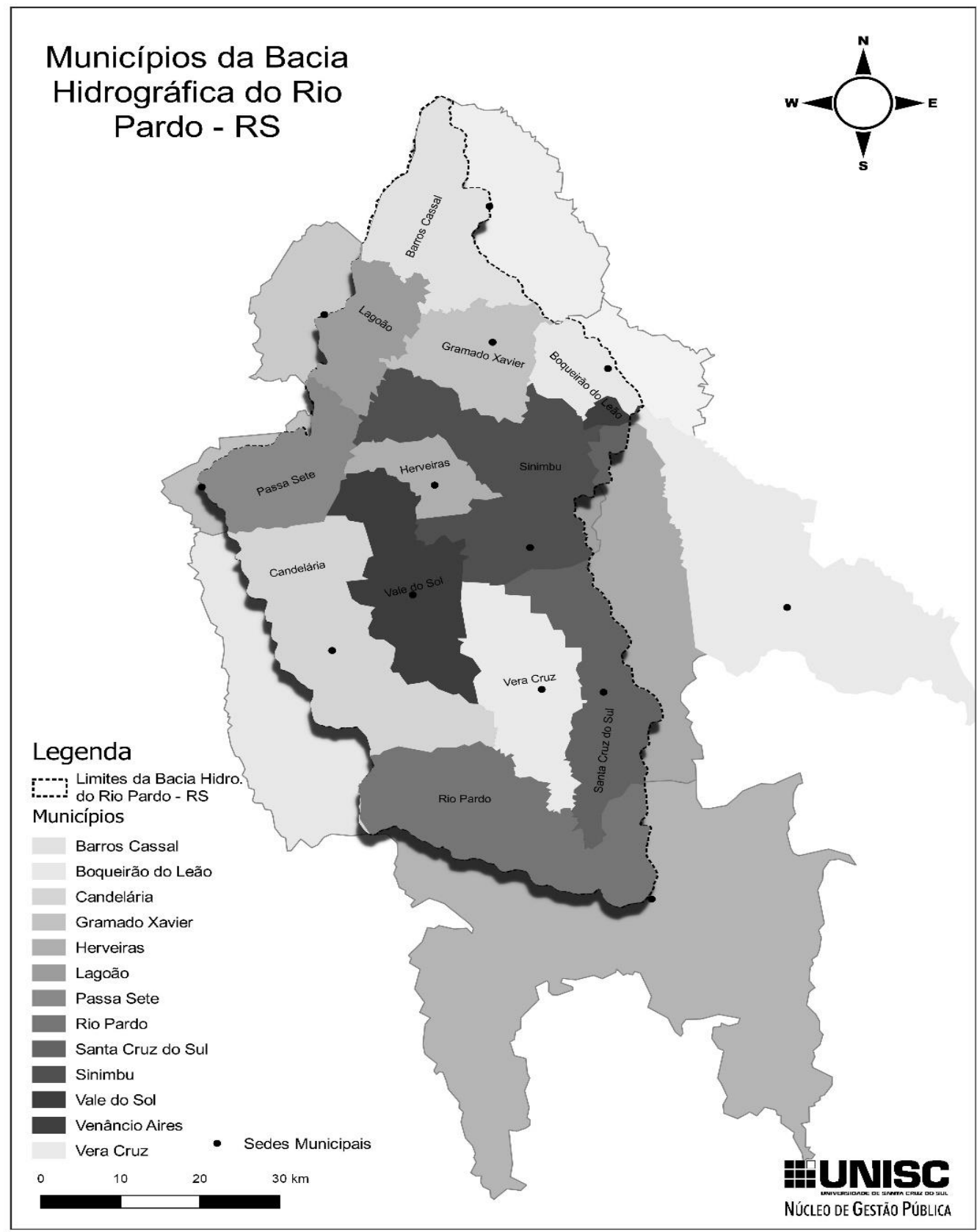

Fonte: Núcleo de Gestão Pública (NGP) da Universidade de Santa Cruz do Sul (UNISC), 2020.

Entre os maiores problemas da bacia, estão:

a) Quantidade de água superficial: às vezes há excesso que provoca cheias, como a de julho de 2020; e por outras vezes com escassez, como se deu de dezembro de 2019 a maio de 2020. Choveu pela primeira vez no ano de 2020, no município de Santa Cruz do Sul, em 11/05/2020, após longos cinco meses de preocupações relacionadas à agricultura e abastecimento da população. O Lago Dourado, maior reservatório de Santa Cruz do Sul, que é o que tem a maior população da bacia, estava em seu limite mínimo.

b) Qualidade da água superficial: degradação de origem urbana e rural. 
c) Morfologia fluvial: assoreamento de cursos d'água, desbarrancamento de margens, retificação de traçado, obstrução de calhas fluviais.

d) Ambiental: déficit de mata ciliar e uso inadequado de solo.

Ressalta-se que estas informações sobre os problemas constam no Plano de Bacia, cujo diagnóstico foi realizado em 2005 e que ainda vigoram em 2020. O Comitê Pardo, responsável pela gestão das águas da Bacia do Pardo, tem um importante compromisso e responsabilidade frente ao planejamento territorial e governança. Se questões ambientas afetam a instalação de novos empreendimentos, o plenário do Comitê Pardo, formado por usuários da água, que utilizam a água como matéria-prima para fins econômicos; representantes da população, que são a sociedade civil organizada, e o poder público têm a missão de discutir o assunto, ouvindo os três tipos de representantes que compõem o seu plenário, de modo a dirimir possíveis conflitos. Desenvolvimento não significa necessariamente crescimento. Há outros fatores a serem considerados, conforme articulação política, histórica e identidade do território, bem como oportunidades.

Usuários da água, representantes da população e poder público, num sistema tripartite de governança, precisam dialogar sobre os temas e um deles refere-se à valores da Cobrança pelo Uso da Água, que como mencionado, não existe no Rio Grande do Sul. De toda forma, se não existe este instrumento, outros mecanismos precisam ser utilizados para que, de fato, a bacia hidrográfica seja recuperada. E o rateio pelo custo de obras foi o adotado pelo Comitê Pardo.

\section{A iniciativa do Comitê Pardo}

Sentindo-se provocados pela morosidade na implementação do sistema referente ao quesito cobrança, membros do Comitê Pardo formaram o Grupo de Trabalho (GT) sobre Rateio de Custo de Obras de Uso e Proteção dos Recursos Hídricos e Agência de Bacia do Pardo, instituído na segunda reunião ordinária do Comitê Pardo, de 4 de junho de 2019, com duração de 180 dias e formado pela diretoria do Comitê Pardo (Universidade de Santa Cruz do Sul-UNISC, Associação dos Fumicultores do Brasil-AFUBRA), Departamento de Gestão de Recursos Hídricos e Saneamento (DRHS), Prefeituras Municipais de Santa Cruz do Sul, Sinimbu e Vera Cruz, Companhia Riograndense de Saneamento (CORSAN), Associação dos Engenheiros Agrônomos do Vale do Rio Pardo (AEAVARP), Associação Riograndense de Empreendimentos de Assistência 
Técnica e Extensão Rural (EMATER) e Associação Gaúcha dos Advogados de Direito Ambiental Empresarial (AGAAE). Esta formação está registrada na Deliberação Comitê Pardo 15/2019 (Comitê Pardo, 2019a).

Uma das primeiras atividades do Comitê foi a realização de uma capacitação para os seus membros quanto às formas de rateio dos custos. Este instrumento seria algo simples se não envolvesse a contribuição de valores financeiros para a execução de obras relacionadas aos recursos hídricos. Na prática, os Comitês de Bacias, que têm a cobrança pelo uso da água já instituídos, não necessitariam realizar o rateio. Mas mesmo se o uso da água impõe a cobrança de recursos financeiros dos atores e usuários, o rateio dos custos, na prática, é uma colaboração, por vontade própria e negociada dentro dos Comitês. No entanto, como se trata de uma negociação, nem sempre os resultados são aqueles esperados porque, conforme afirma Granovetter (2007), as negociações geralmente dependem do comportamento dos atores e das instituições e estes são afetados pelas relações sociais. Ora, se os usuários da água, que necessariamente pagam pelo seu uso, onde existe, mantém relações próximas, seja por associações comerciais ou federações, é de se esperar que estas perpassem as relações de ordem pessoal e cheguem nas profissionais.

Assim, infere-se que o rateio, sendo uma negociação, sofra interferências do tipo de relações, profissionais e pessoais, que estes usuários da água detenham. Ou seja, determinados usuários podem não querer participar do rateio se outro usuário, que não possua boa relação com este, também participe. Outrossim, pode ocorrer que um usuário que participe do rateio tenha tanta influência que acabe por alavancar a participação das demais instituições no rateio. Ao mesmo tempo, a eventual decisão do usuário influente de declinar da iniciativa poderia implicar no abandono de parceiros no rateio.

Ao se referir às relações de poder, Bourdieu (2006) afirma que a competição dos atores para a determinação do poder, está presente na busca de dominação e controle sobre os demais, seja no aspecto econômico-financeiro ou social. Essa dominação, que pode ser a de classe, pode ser inferida através do conceito de habitus, um princípio gerador que classifica as práticas. Assim, a participação social é determinada pela herança social do indivíduo. A classe dominante é a que detém maior capital econômico e desse modo é preciso que o ator em desvantagem reconheça o seu papel e lugar perante o dominador. Para Foucault (2011), as relações sociais são sempre de poder, e não estaria somente em nível de Estado, mas em nível de indivíduo. O poder seria exercido discretamente, através de jogos de olhares e gestos, não como a tirania de um rei. 
Torna-se invisível, mas presente. Neste contexto, diante de tantas variáveis e sutilezas, está o desafio de um Comitê que é a negociação entre os atores considerando essas relações de poder, que existem, discretamente no âmbito do território.

Voltando ao ponto de partida que era a constituição de um Grupo de Trabalho (GT) dentro do Comitê Pardo, este GT, que contou também com a participação de representante da Secretaria Estadual de Meio Ambiente e Infraestrutura (SEMA/RS), em 4 de junho, promoveu a discussão quanto à necessidade da criação de uma Agência de Bacia, no caso uma organização jurídica de direito privado que pudesse auxiliar o Comitê Pardo na execução dos projetos de recuperação da bacia e também a definição dos critérios de rateio dos custos, que não estão especificados de forma didática na lei, tanto federal quanto estadual. O grupo de trabalho (GT) se reuniu em seis ocasiões ao longo do ano de 2019. No primeiro encontro, em 4 de julho, analisou-se o organograma de algumas Agências de Bacias com Cobrança pelo Uso da Água no Brasil. Também fez parte dos debates a experiência paradigmática francesa no sentido de organização de estrutura semelhante.

No segundo encontro, em 20 de agosto, foi ouvido o relato do presidente do Comitê da Bacia Hidrográfica do Rio Santa Maria sobre a mobilização social da Associação de Usuários do Rio Santa Maria (AUSM). No terceiro encontro, ocorrido em 3 de setembro, houve o relato do presidente da Agência Reguladora de Serviços Públicos Delegados de Santa Cruz do Sul (AGERST) sobre a personalidade jurídica da Agência, considerando os aspectos da sua instituição, funcionamento e desafios. No quarto encontro, em 24 de setembro, os membros estudaram a regulamentação jurídica das Organizações da Sociedade Civil de Interesse Público (OSCIP), através da exposição da Lei Federal 9.790/1999, e esboçaram o primeiro desenho da pretendida Agência. No quinto encontro, em 29 de outubro, os membros realizaram os ajustes finais do esboço de Agência, que seria apresentado na quinta reunião ordinária do Comitê Pardo, de 19 de novembro daquele ano. Na Figura 2 apresenta-se a cronologia dos trabalhos do GT.

Na quinta reunião ordinária do Comitê Pardo, os membros do GT apresentaram aos componentes do plenário do Comitê, o modelo de Agência, devendo esta ser uma associação de direito privado sem fins lucrativos, conforme os estudos do grupo. Discutindo item a item, chegou-se à Deliberação Comitê Pardo 16/2019 (Comitê Pardo, 2019b) e esta foi aprovada. Mas faltava ainda tratar sobre a questão do rateio dos custos e, por isso, os membros do GT novamente se reuniram, no sexto encontro, em 17 de dezembro, para discutir os critérios do instrumento. 
Figura 2. Cronologia das atividades do GT Rateio e Agência de Bacia

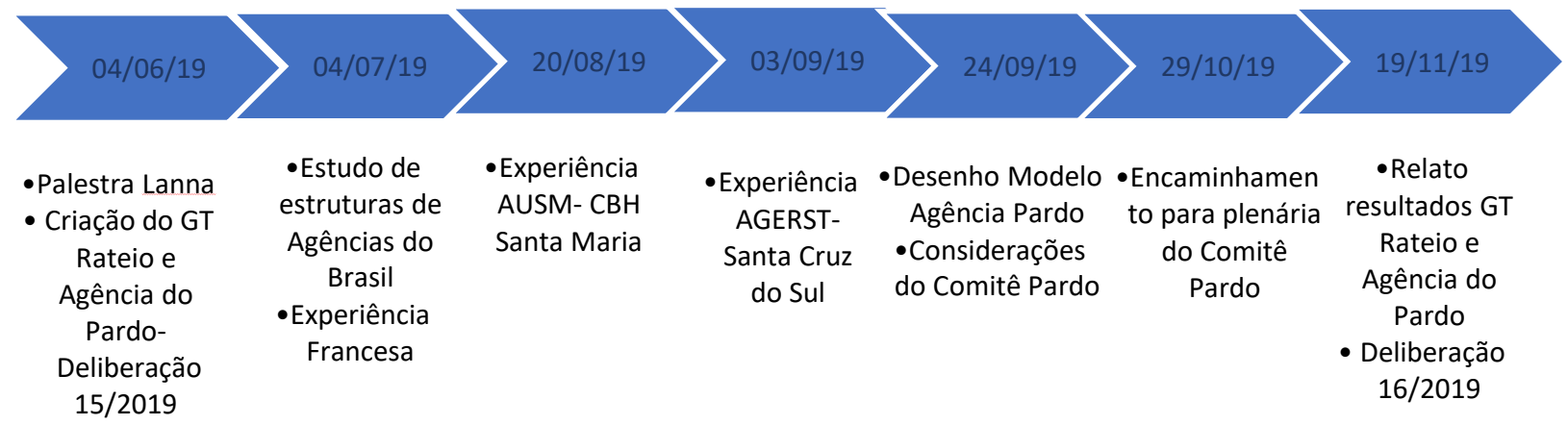

Fonte: elaborado pelos autores (2020).

Em pesquisa realizada pela secretaria executiva do Comitê Pardo, dos 26 estados da federação, apenas o Estado do Piauí não possuía em sua legislação estadual de recursos hídricos o item rateio de custos. Os Estados em que havia um capítulo ou seção exclusiva para tratar sobre o rateio foram: A-Região Sul: Rio Grande do Sul, Santa Catarina e Paraná; B-Região Sudeste: São Paulo e Minas Gerais; C-Região Centro-Oeste: Goiás; D-Região Nordeste: Alagoas, Ceará e Paraíba, e E-Região Norte: Pará, Roraima e Amapá.

No Rio Grande do Sul o rateio está descrito em tópico especial no artigo 34 da lei estadual 10.350/1994, sendo que no artigo 19, estão elencadas as competências dos Comitês de Bacias, onde se insere o rateio de custos. E no artigo 20, este aparece como competência das Agências de Bacias também. Além disso, o artigo 27 versa que o rateio de custos também deveria fazer parte dos Planos de Bacias, contudo, não menciona o rateio de custos como competência do Conselho Estadual de Recursos Hídricos ( $\mathrm{CRH}$ ) e tampouco que ele integre o Fundo Estadual de Recursos Hídricos (FRH).

Assim, ao afirmar que é o Comitê de Bacia que tem a atribuição de realizar o rateio dos custos de obras de interesse comum a serem executadas na bacia hidrográfica e não havendo subordinação ao CRH para homologação, pelo compreendido do disposto em legislação, o GT do Comitê Pardo elaborou os critérios para o mesmo. A aprovação dos critérios de rateio estava prevista para ocorrer na reunião ordinária de 17 de março de 2020, porém houve o cancelamento da mesma devido à impossibilidade de encontros presenciais devido às orientações dos decretos estaduais e municipais que dispunham sobre as medidas de prevenção ao novo coronavírus (COVID-19). A partir desta data, as reuniões do Comitê Pardo passaram a ser realizadas na modalidade virtual, por videoconferência, sempre registradas em atas, conforme modelo 
presencial. Apesar de finalizados os critérios no final de dezembro de 2019, o Comitê Pardo precisou aguardar a retomada das reuniões, ainda que virtuais, para que o plenário pudesse apreciar os critérios de rateio de custos que foram aprovados na segunda reunião ordinária do Comitê Pardo, de 21 de julho de 2020, compondo a Deliberação Comitê Pardo 18/2020 (Comitê Pardo, 2020), que estabelece os critérios para o Rateio pelo Custo de Obras de Uso e Proteção de Recursos Hídricos para a Bacia do Pardo.

Esta deliberação apresenta de forma simples e didática os critérios definidos para o rateio e sua importância reside no fato de que foi elaborada a partir da experiência dos membros do Comitê Pardo e ajustada à realidade. Em uma comparação muito simplificada, corresponderia a um grande "acordo de cavalheiros", porém redigido em forma de documento e publicado no site do Comitê Pardo, primando pelo princípio da transparência. Estes termos não são definitivos, pois à medida em que o Comitê Pardo for operacionalizando, certamente haverá necessidade de ajustes, com o devido monitoramento sobre o que frutificou com bons resultados ou nem tanto.

Dentre os critérios, o primeiro a ser estabelecido foi a definição do projeto a ser rateado, considerando o Plano da Bacia Hidrográfica e os cenários: bacia limpa, poluída e intermediário. O Plano de Bacia fornece a diretriz do que é necessário para a recuperação da bacia hidrográfica e os cenários permitem avaliar as prioridades, como situação de escassez de água ou mesmo poluição. Após, procede-se à identificação dos benefícios do projeto, definindo indicadores e resultados esperados, pois sem isso não será possível fazer uma avaliação do que surtiu efeito ou não, sendo também uma forma de prestação de contas à sociedade.

Parte-se para a identificação dos beneficiários diretos e indiretos do projeto, utilizandose, inclusive, dos instrumentos de gestão disponíveis, citando como exemplo o Sistema de Outorga de Água do Rio Grande do Sul (SIOUT), onde estão cadastrados os usuários da água, por município e bacia hidrográfica. O Comitê Pardo acompanha a evolução do cadastro em sua bacia desde 2017, quando o sistema, sendo online e de livre consulta, permite reconhecer os atores da bacia. Uma vez identificados, haverá a consulta prévia dos beneficiários diretos do projeto nas possíveis formas de participação do rateio dos custos, que podem ser: horas técnicas de profissionais, materiais e equipamentos, insumos e outros desde que afins com o projeto. A operação pretendida possibilita otimizar gastos e/ou recursos, atividades, tempo, entre outros benefícios, em prol da recuperação da Bacia, no sentido de aproveitar os recursos financeiros e outros já existentes na Bacia, por isso não se priorizou um recurso em detrimento de outro. Todos os recursos são bem-vindos e necessários. 
Como há a possibilidade de mais instituições apresentarem interesse em participar do rateio, de forma voluntária, considerou-se a captação de outros parceiros interessados no rateio dos custos do projeto. A negociação deverá iniciar no Comitê e ser encaminhada à Associação Pró-Gestão das Águas da Bacia Hidrográfica do Rio Pardo - AGEPARDO para a execução da ação e/ou projeto. E como benefício pela participação do rateio dos custos os participantes terão prioridade de outorga em situação de escassez de água, observado o disposto na Lei Federal 9.433/1997 e Lei Estadual 10.350/1994. A partir destas considerações iniciais, os critérios, como acordo entre os atores, podem fornecer uma diretriz para as negociações, que sempre serão tratadas conforme a peculiaridade e natureza do projeto a ser rateado.

\section{A organização jurídica de direito privado, os critérios de rateio e o termo de referência}

Após a última reunião ordinária do Comitê Pardo de 2019, foi dado início aos procedimentos de criação da organização jurídica de direito privado. Em 9 de janeiro de 2020 foi criada a Associação Pró-Gestão das Águas da Bacia Hidrográfica do Rio Pardo (AGEPARDO), de iniciativa de pessoas físicas, sendo alguns membros do Comitê Pardo. A AGEPARDO tem uma estrutura enxuta, composta por assembleia geral, conselho de administração, conselho fiscal e diretoria. O presidente do Comitê Pardo integra o Conselho de Administração, conforme regimento interno da Associação, participando das reuniões dela. E para que haja um processo transparente, a AGEPARDO participa das reuniões do Comitê Pardo, com tempo definido para atualizar o plenário sobre suas atividades.

Porém, é preciso registrar que anteriormente à criação da AGEPARDO e dos critérios de rateio de custos dos projetos, o Comitê Pardo, desde 2018, já vinha trabalhando a partir da necessidade da execução de iniciativas de recuperação de trechos da Bacia do Pardo que estavam visivelmente prejudicados por falta de mata ciliar e processos erosivos. Para tanto, contatou a SEMA e solicitou que fosse inserido no orçamento dos anos de 2018 e 2019 do Fundo Estadual de Recursos Hídricos (FRH) um valor para a destinação de contratação de empresa que elaborasse projetos executivos para as ações de recuperação de trechos do Rio Pardinho nos municípios de Sinimbu, Vera Cruz e Santa Cruz do Sul. Esta destinação de recursos seria possível desde que se elaborasse um Termo de Referência (TR) com o que se pretendia. No final do ano de 2018, o grupo formado por representantes das três prefeituras municipais, juntamente com 
o Departamento de Gestão de Recursos Hídricos e Saneamento (DRHS/SEMA), delimitaram os trechos que consideraram prioritários para a recuperação.

Pois, se em 2018 o trabalho era delimitar a área de recuperação e solicitar ao Estado que contratasse uma empresa para elaborar os projetos de execução de recuperação, em 2019 o foco se deteve na definição de uma Agência de Bacia e critérios de rateio de custos. O Comitê Pardo vem trabalhando arduamente para que a sua Bacia Hidrográfica seja recuperada, com auxílio dos dispositivos legais, pois tem competência deliberativa. Quanto ao TR, a SEMA dispôs o prazo de até 10 de junho de 2020 para o recebimento de orçamentos das empresas dispostas a elaborarem os projetos de recuperação dos trechos dos municípios citados. Esta estimativa de custo é a etapa inicial para a contratação dos estudos pelo Estado para lançar os editais de licitação.

Os membros do Comitê Pardo aguardam que uma empresa seja contratada, pois com os projetos executivos em mãos, será possível canalizar os esforços em busca de financiamentos para estas ações de recuperação ambiental. Como o Comitê Pardo não pode receber recursos financeiros, por não ter esta atribuição e nem possuir personalidade jurídica, a AGEPARDO pode, e tendo os critérios de rateio de custos fixados, a partir da definição dos beneficiários diretos e indiretos de cada projeto, pode-se ir em busca destes atores e definir o valor que caberia e poderia ser disponibilizado pelos stakeholders para o projeto conforme as regras estabelecidas. Assim, os dois instrumentos estão unidos, AGEPARDO e critérios de rateio de custos, e alinhados ao TR do Rio Pardinho, demonstrando que há uma sequência no planejamento de ações deste Comitê que procura encontrar alternativas para que sua Bacia seja recuperada desde 2018.

\section{Considerações finais}

Diante do que se expôs, depreende-se que a legislação de recursos hídricos, tanto federal quanto estadual, preocupou-se em ajustar todos os mecanismos de forma que uma estrutura dependeria da outra para seu funcionamento. Acontece que a legislação não está atrelada às manifestações político-administrativas e entraves do sistema de governo, como no caso os recursos financeiros que envolveriam a criação de mais uma estrutura administrativa no Estado. Deste modo, novas proposições são necessárias para que de fato as bacias hidrográficas sejam recuperadas e a gestão de recursos hídricos cumpra a sua verdadeira função. Como apregoam os membros do Comitê Pardo, é preciso trabalhar com o que se dispõe hoje, sem criar novas estruturas estatais, e recorrendo a recursos financeiros disponíveis através de editais e recursos 
financeiros privados por meio de corporações que têm o desejo de contribuir para a recuperação do meio ambiente, para o benefício coletivo e desenvolvimento regional no sentido da garantia de recursos hídricos para todos os usos, consultivos e não consultivos.

Como governança territorial, o Comitê Pardo atua de forma a planejar o território decidindo sobre os aspectos da gestão de recursos hídricos conforme preconiza a legislação através de seus três grupos de atores, dentre eles a sociedade civil. Conflitos e interesses diferentes existem dentro dos plenários dos Comitês de Bacias, mas no caso da construção destes mecanismos alternativos, o processo ocorreu de forma consensuada visto que os grupos de trabalho sempre foram muito livres, permitindo a participação de diversas entidades, conforme vontade das mesmas.

Analisar e descrever o processo de criação de instrumentos de gestão dos recursos hídricos pelo Comitê Pardo a partir de uma construção coletiva que inovou no aspecto metodológico em busca de uma alternativa para melhoria da gestão das águas da Bacia do Pardo, foram os objetivos do estudo que gerou este artigo. Para o futuro, acredita-se que esse processo e essa metodologia poderão servir como referência para o Sistema de Recursos Hídricos e, também, espera-se que seja possível produzir novos resultados mostrando a evolução desse processo, a partir desses instrumentos, no Comitê Pardo.

\section{Referências}

ARENDT, Hannah. A condição humana. 10aㅡ ed. 6a reimpr. Rio de Janeiro: Forense universitária, 2007.

Ata de Instalação Comitê Pardo 01/1999. Comitê Pardo, 1999. Disponível em: < http://www.comitepardo.com.br/atas/1999/ata01 99.pdf>. Acesso em: 03/07/2020.

BOURDIEU, Pierre. A distinção: crítica social do julgamento. Porto Alegre: Zouk, 2006.

BRASIL. Lei n. 9.433, de 8 de janeiro de 1997. Institui a Política Nacional de Recursos Hídricos, cria o Sistema Nacional de Gerenciamento de Recursos Hídricos, regulamenta o inciso XIX do art. 21 da Constituição Federal, e altera o art. 1ํ da Lei no 8.001, de 13 de março de 1990, que modificou a Lei no 7.990, de 28 de dezembro de 1989. Diário Oficial [da] República Federativa do Brasil, Brasília, DF, 9 jan. 1997. Disponível em:

http://www.planalto.gov.br/ccivil 03/leis/L9433.htm. Acesso em: 03/07/2020.

BRITO, Patrícia Lustosa; ANJOS, Rafael Sanzio Araújo. Planejamento Territorial: O Município X A Bacia Hidrográfica. Revista Eletrônica: Tempo - Técnica - Território, V.1, N.1 (2010), p. 26:42. Disponível em:< http://inseer.ibict.br/ciga/index.php/ciga/article/viewFile/164/123>. Acesso em 03/07/2020. 
Deliberação Comitê Pardo 15/2019. Comitê Pardo, 2019a. Disponível em:< http://www.comitepardo.com.br/deliberacoes/2019/Deliberacao2015.2019.pdf>. Acesso em $13 / 07 / 2020$.

Deliberação Comitê Pardo 16/2019. Comitê Pardo, 2019b. Disponível em:< http://www.comitepardo.com.br/deliberacoes/2019/Deliberacao2016.2019.pdf>. Acesso em $13 / 07 / 2020$.

Deliberação Comitê Pardo 18/2020. Comitê Pardo, 2020. Disponível em:< http://www.comitepardo.com.br/deliberacoes/2020/Deliberacao-18.2020.pdf>. Acesso em: 22/07/2020.

FLORES, Murilo. A identidade cultural do território como base de estratégias de desenvolvimento - Uma visão do estado da arte. Santiago, Chile: RIMISP, 2006.

FOUCAULT, Michel. Vigiar e punir: nascimento da prisão. 39.ed. Petrópolis, RJ: Vozes, 2011.

GRANOVETTER, M. Ação econômica e estrutura social: o problema da imersão.

Revista de Administração de Empresas - FGV, v. 6, n. 1, 2007. Disponível em:< https://rae.fgv.br/sites/rae.fgv.br/files/artigos/10.1590S1676-56482007000100010.pdf>. Acesso em: 31/07/2020.

HAESBAERT, Rogério. Território e Multiterritorialidade: um Debate. GEOgraphia - Ano IX - No 17. P.19-45, 2007.

KAUFFMAN, Dora. A força dos "laços fracos" de Mark Granovetter no ambiente do ciberespaço. Galaxia (São Paulo, Online), n. 23, p. 207-218, jun. 2012.

OBSERVATÓRIO DA GOVERNANÇA DAS ÁGUAS. OGA, 2020. Governança. Disponível em: $<$ https://observatoriodasaguas.org/governanca/>. Acesso em 31/07/2020.

PALHETA DA SILVA, João Márcio. Poder, governo e território na sociedade contemporânea. Série Estudos e Ensaios / Ciências Sociais / FLACSO-Brasil - junho /2009.

PECQUEUR, Bernard. A guinada territorial da economia global. Política \& Sociedade - Revista de Sociologia Política, Florianópolis, Vol 8, no 14, p. 79-105, abril de 2009.

PIRES, Elson Luciano Silva; FUINI, Lucas Labigalini; MANCINI, Rodrigo Furgieri; PICCOLI NETO; Danilo. A Governança Territorial o Brasil: Conceitos e Modalidades. Anais do I Circuito de Debates Acadêmicos. II Conferência do Desenvolvimento (CODE) 2011. Instituto de Pesquisa Econômica Aplicada (IPEA). Brasília/DF. Disponível em:

https://www.ipea.gov.br/code2011/chamada2011/pdf/area7/area7-artigo10.pdf. Acesso em 03/07/2020.

PIRES, Elson Luciano Silva; NEDER, Ricardo Toledo. A Governança Territorial no Brasil: As Instituições, os Fatos e os Mitos. Geografia e Pesquisa. v. 2, n. 2, 2008. Disponível em:< file:///C:/Users/Acer/Downloads/85-192-1-SM.pdf>. Acesso em: 03/07/2020.

PLANO DE BACIA DO RIO PARDO. Etapa A. Disponível em: < http://www.comitepardo.com.br/planopardo/relatoriodiagnostico/REAcompleto.pdf>. Acesso em: 03/07/2020.

PORTO, Monica F. A.; PORTO, Rubem La Laina. Gestão de bacias hidrográficas. Revista Estudos Avançados. vol.22 no.63. São Paulo, 2008. Disponível em:< https://doi.org/10.1590/S010340142008000200004>. Acesso em 03/07/2020.

RAFFESTIN, Claude. Por uma Geografia do Poder. França. São Paulo: Ática, 1993. 
RIO GRANDE DO SUL. Lei n. 10.350, de 30 de dezembro de 1994. Institui o Sistema Estadual de Recursos Hídricos, regulamentando o artigo 171 da Constituição do Estado do Rio Grande do Sul. Diário Oficial [do] Estado do Rio Grande do Sul, Porto Alegre, RS, 1o jan. 1995 (1994b). Disponível em: http://www.al.rs.gov.br/filerepository/repLegis/arquivos/10.350.pdf. Acesso em 03/07/2020.

RIO GRANDE DO SUL. Decreto Estadual 39.116, de 08 de dezembro de 1998. Cria o Comitê de Gerenciamento da Bacia do Rio Pardo. Diário Oficial [do] Estado do Rio Grande do Sul, Porto Alegre, RS, 8 dez. 1998. Disponível em:< http://www.al.rs.gov.br/legis/M010/M0100099.ASP?Hid Tipo=TEXTO\&Hid TodasNormas=533 9\&hTexto=\&Hid IDNorma=5339>. Acesso em: 03/07/2020.

SANTOS, Milton. A Natureza do Espaço-Técnica e Tempo. Razão e Emoção. São Paulo: Editora da Universidade de São Paulo, 1996.

SANTOS, Milton. O Território e o Saber Local: algumas categorias de análise. Cadernos IPPUR, UFRJ, Ano XIII, no 2, Ago-Dez 1999.

SMITH, Adam. A Riqueza das Nações: Investigação sobre sua Natureza e suas Causas. In.: Os

Economistas. Adam Smith. A Riqueza das Nações: Investigação sobre sua Natureza e suas Causas. Com a Introdução de Edwin Cannan, volume I, Apresentação de Winston Fritsch e Tradução de Luiz João Baraúna, São Paulo: Nova Cultural, 1996.

TUCCI, Carlos Eduardo Morelli. Hidrologia: ciência e aplicação. 2.ed. Porto Alegre: ABRH/Editora da UFRGS, 1997. (Col. ABRH de Recursos Hídricos, v.4). 